\title{
Longitudinal changes of brain microstructure and function in nonconcussed female rugby players
}

Kathryn Y. Manning, PhD, Jeffrey S. Brooks, MSc, James P. Dickey, PhD, Alexandra Harriss, MSc, Lisa Fischer, MD, Tatiana Jevremovic, MD, Kevin Blackney, MSc, Christy Barreira, BSc, Arthur Brown, PhD, Robert Bartha, PhD, Tim Doherty, MD, PhD, Douglas Fraser, MD, PhD, Jeff Holmes, PhD, Gregory A. Dekaban, PhD, and Ravi S. Menon, PhD

Neurology ${ }^{\circledR}$ 2020;95:e402-e412. doi:10.1212/WNL.0000000000009821

\author{
Correspondence \\ Dr. Menon \\ rmenon@robarts.ca
}

\begin{abstract}
Objective

To longitudinally assess brain microstructure and function in female varsity athletes participating in contact and noncontact sports.

\section{Methods}

Concussion-free female rugby players $(\mathrm{n}=73)$ were compared to age-matched (ages 18-23) female swimmers and rowers $(\mathrm{n}=31)$ during the in- and off-season. Diffusion and resting-state fMRI (rs-fMRI) measures were the primary outcomes. The Sports Concussion Assessment Tool and head impact accelerometers were used to monitor symptoms and impacts, respectively.
\end{abstract}

\section{Results}

We found cross-sectional (contact vs noncontact) and longitudinal (in- vs off-season) changes in white matter diffusion measures and rs-fMRI network connectivity in concussion-free contact athletes relative to noncontact athletes. In particular, mean, axial, and radial diffusivities were increased with decreased fractional anisotropy in multiple white matter tracts of contact athletes accompanied with default mode and visual network hyperconnectivity $(p<0.001)$. Longitudinal diffusion changes in the brainstem between the in- and off-season were observed for concussion-free contact athletes only, with progressive changes observed in a subset of athletes over multiple seasons. Axial diffusivity was significantly lower in the genu and splenium of the corpus callosum in those contact athletes with a history of concussion.

\section{Conclusions}

Together, these findings demonstrate longitudinal changes in the microstructure and function of the brain in otherwise healthy, asymptomatic athletes participating in contact sport. Further research to understand the long-term brain health and biological implications of these changes is required, in particular to what extent these changes reflect compensatory, reparative, or degenerative processes.

\section{MORE ONLINE}

- CME Course

NPub.org/cmelist 


\section{Glossary}

$\mathbf{A D}=$ axial diffusion; $\mathbf{C I}=$ confidence interval; $\mathbf{D M N}$ = default mode network; $\mathbf{D T I}=$ diffusion tensor imaging; FA = fractional anisotropy; FMRIB = Functional Magnetic Resonance Imaging of the Brain; FSL = FMRIB Software Library; MD = mean diffusion; PCC = posterior cingulate cortex; RD = radial diffusion; $\mathbf{R O I}$ = region of interest; rs-fMRI = resting-state fMRI; RSN = resting-state network; SCAT3 = Sports Concussion Assessment Tool.

Athletes engaged in contact sports experience repetitive subclinical impacts over the course of multiple seasons. While it remains controversial, recent studies suggest that these seemingly innocuous impacts could have a significant cumulative effect on brain health. ${ }^{1-3}$ Although some studies have not reported symptoms or cognitive deficits in nonconcussed contact sport athletes, ${ }^{4}$ others have, with significant relationships between cognitive measures and the age at first exposure to contact sport, distal concussion history, and years of contact play. ${ }^{2,3,5-7}$ This is reinforced by task-based ${ }^{7}$ and resting state (rs)-fMRI studies ${ }^{8}$ that have identified altered functional connectivity as a result of subclinical impacts, showing that differences between contact and noncontact athletes at the beginning of season suggest cumulative effects from years of contact play. ${ }^{8}$

Diffusion tensor imaging (DTI) has also revealed alterations in the corpus callosum ${ }^{9,10}$ that correlated with the number of subclinical impacts and poor memory performance. ${ }^{11}$ However, it is unclear how these imaging markers of brain microstructure and function relate and evolve over time in contact relative to noncontact athletes. In particular, it is essential to understand exactly how they vary throughout a season and over consecutive years of contact play and whether a history of concussion influences this trajectory. By comparing contact and noncontact high-intensity athletes, we aimed to determine whether there are unique structural and functional brain imaging changes associated with concussionfree contact play compared to noncontact play, the in- and offseason periods, and history of concussion, as well as across concussion-free consecutive years of contact play.

\section{Methods}

In this study, we followed up a large cohort of nationally competitive women's varsity rugby athletes (contact group) over multiple concussion-free seasons (including a subset of athletes who participated in 2 seasons) and compared them to a single season of age-matched female varsity rowers and swimmers (noncontact group). Demographics are given in table 1. DTI and rs-fMRI data were acquired during the in-season and off-season if the athlete did not experience a diagnosed concussion within 6 months of entry into the study. A sports medicine physician monitored any clinical symptoms and cognitive and memory performance using the Sports Concussion Assessment Tool (SCAT3). ${ }^{12}$ To characterize impact forces, a subset of rowers and rugby players wore head impact accelerometer sensor bands during practice and competition.

\section{Standard protocol approvals, registrations, and patient consents}

The Western University Health Sciences Research Ethics Board approved the study, and we obtained written informed consent from each athlete at the beginning of each season.

\section{Study design}

The women's varsity rugby team was followed up closely over a 5-year period of national competition, and MRI and clinical data were acquired from 73 contact athletes during the inseason and 63 contact athletes during the off-season (includes repeated data from returning athletes). These data were compared to longitudinal data from concussed contact athletes in a previous publication in which details of their season are described. ${ }^{13,14}$

A total of 31 noncontact age-matched $(p>0.3)$ athletes were assessed during the in-season and 23 during the off-season. Noncontact athletes (i.e., rowers and swimmers) began regular training and practices while in-season data were collected (September). Rowers trained $6 \mathrm{~d} / \mathrm{wk}$ with weekly regatta competitions until November. Swimmers trained 6 days a week with monthly swim meets until March. The off-season data were acquired $\approx 6$ months after in-season data collection and 2 to 3 months after the contact rugby practices and rowing season ended, whereas the swimming off-season scans were obtained directly after their season ended. Athletes reported in this study had not experienced a diagnosed concussion (or concussion-related symptoms) within 6 months of data collection. The SCAT3 data were collected by a sports medicine physician according to the standard instructional guidelines. $^{12}$

\section{Head impact measurements and analysis}

A subset of rugby players and rowers wore a headband instrumented with a head impact sensor (GFT3, Artaflex, Inc, Markham, Ontario, Canada) positioned at the occipital bone. Each sensor contains a triaxial accelerometer and a triaxial gyroscope that measure linear acceleration ( $1 \mathrm{~g}$ resolution) and rotational velocity $(1 \%$ s resolution), respectively. When an impact exceeded a linear acceleration of $15 g$, the sensor triggered and recorded 8 milliseconds of the impact data preceding the threshold and 32 milliseconds of impact data after the threshold. Linear accelerations were sampled at $3,000 \mathrm{~Hz}$ and filtered through an onboard analog low-pass filter with a cutoff frequency of $300 \mathrm{~Hz}$. Rotational velocity was sampled at $800 \mathrm{~Hz}$ and low-pass filtered with a cutoff frequency of $100 \mathrm{~Hz}$. All data collected were recorded in the onboard memory of the sensors. Impact data were uploaded 
Table 1 Demographics

\begin{tabular}{llll}
\hline Group & No. of included datasets & Average age (SD), y & Average no. of previous concussions (SD) \\
\hline Contact athletes during the in-season & 70 & $19.95(1.50)$ & $0.53(0.76)$ \\
\hline Contact athletes during the off-season & 60 & $20.13(1.43)$ & $0.57(0.81)$ \\
\hline Noncontact athletes during the in-season & 31 & $19.61(1.87)$ & 0 \\
\hline Noncontact athletes during the off-season & 23 & $20.07(1.62)$ & 0 \\
\hline
\end{tabular}

Details for the study participants.

to a cloud-based server after each session, and each impact was date and time stamped. Peak linear acceleration and peak rotational velocity for each impact were calculated.

Impacts were verified with video taken during the sessions. Game and practice videos were recorded and analyzed during 1 rowing practice (60 minutes), 1 preseason rugby game (90 minutes), and 2 rugby contact practices (60 minutes each) with a Sony (Tokyo, Japan) Vixia HD camera mounted to a telescoping tower (EVS25, Endzone Video Systems, Sealy, TX). Each video was uploaded to a video analysis software program (dba HUDL, Agile Sports Technologies, Inc, Lincoln, NE) and reviewed.

Head impact data can be skewed because of the high number of low-magnitude impacts that are measured during a session. Therefore, a Shapiro-Wilks test was used to determine the normality of the distribution of the impact measures: peak linear acceleration, peak rotational velocity, and maximum head injury criteria. If the impact measures were not normally distributed $(p<0.05)$, then nonparametric Wilcoxon sum-ofranks analyses were conducted on the data, and the medians and interquartile ranges were determined for the impact measures comparing games and practices. The total number of impacts for the rowing sessions and total number of impacts in games and practices were determined.

\section{MRI analysis}

All MRI data were acquired on a 3T MR scanner (Prisma, Siemens, Munich, Germany) with a 32-channel head coil. The imaging sequence details have been previously reported. ${ }^{14}$ Diffusion data were analyzed with the Functional Magnetic Resonance Imaging of the Brain (FMRIB) Software Library (FSL version 6.0; Oxford, UK). Diffusion data were assessed for large motion and artifacts on a volume-by-volume basis. Data were corrected simultaneously for motion and eddy current distortion. Maps of diffusion measures including mean diffusion (MD), fractional anisotropy (FA), radial diffusion $(\mathrm{RD})$, and axial diffusion $(\mathrm{AD})$ were created. Once these maps were created in diffusion space, the images were preprocessed to perform tract-based spatial statistics. This involved eroding the FA images slightly to remove outliers (near the edge of the brain and the bottom and top slices) and nonlinear registration to standard space using the FMRIB58
FA 1-mm isotropic image. Once transformed to standard space, a skeletonized FA image was created using an FA threshold of 0.2. The other diffusion metrics were projected onto this same skeleton and statistically compared among groups of participants on a voxel-wise basis using permutation and threshold-free cluster enhancement, correcting for multiple comparisons across voxels $(p<0.001$ with Bonferroni correction).

rs-fMRI data were preprocessed with the fMRI Expert Analysis Tool in FSL and included brain extraction, affine rigidbody motion correction, 5-mm spatial smoothing, and highpass frequency filtered at $0.01 \mathrm{~Hz}$. Data with excessive motion (>0.5-mm relative mean displacement) were omitted. The rsfMRI data were registered to their respective anatomic image, which was in turn transformed to standard space. Preprocessed data were denoised further with independent component analysis in which components related to noise artifacts (activation primarily outside the brain, within the CSF, or within the white matter or containing high-frequency profiles) were removed through regression from the preprocessed data. Independent component analysis was used once again on the cleaned data to identify 10 resting-state networks (RSNs) by correlating with previously identified RSNs robustly found in healthy participants. ${ }^{15}$ Dual regression algorithms were used to create individual RSN maps for each participant and session, and then RSNs were assessed for statistical group differences (among in- and off-season contact [rugby] and noncontact athletes [rowers and swimmers]) after correction for multiple comparisons (required voxel-wise corrected $p<0.01$ with Bonferroni correction) with the randomise permutation tool. These networks included the default mode network (DMN), lateral visual network, and cerebellar RSNs that were chosen due to previous concussion-related findings from our group.

\section{Statistical analysis}

Statistical analysis was performed with Prism 7 (GraphPad Software, La Jolla, CA), GraphPad Software (GraphPad Software), and MATLAB (MathWorks, Inc, Natick, MA). Imaging regions of interest (ROIs) with significant differences among groups were explored further with a linear mixedeffects model within MATLAB to evaluate the main effect of participant group (i.e., contact vs noncontact), time (i.e., in- vs 
off-season), and interaction between time and group while setting participant number as a random factor to account for repeated years of study participation (required $p<0.003$ Bonferroni correction for number of models run). SCAT3 composite scores that significantly changed between the inseason and off-season were used in the model as possible predictors. Imaging ROIs were analyzed with a pair-wise analysis (within participant) between in- and off-season data ( $p<0.001$ with Bonferroni correction). The brainstem ROI was investigated due to our previous finding of linked decreases in $\mathrm{MD}$ and $\mathrm{AD}$ and increased $\mathrm{FA}$ for in-season and 24- to 72-hour postconcussion data compared to off-season data. ${ }^{14}$ For a subset of contact athletes with 2 years of concussion-free data $(n=12)$, we examined repeated withinparticipant measures over time using repeated-measures analysis of variance. In an attempt to understand whether current participation in contact play and previous concussion history were driving any imaging changes, we also compared contact athletes with and without a concussion history using a 2 -tailed independent $t$ test $(p<0.05)$. We performed a correlation analysis to evaluate whether any white matter changes were related to functional connectivity.

\section{Data availability}

All anonymized data are available to qualified investigators on request.

\section{Results}

Results include data from 70 concussion-free contact athletes during the in-season, 60 concussion-free contact athletes during the off-season (lost participants included 3 datasets that had excessive motion during the rs-fMRI acquisition and 8 athletes who experienced a concussion before the off-season scan), 31 noncontact athletes during the in-season, and 23 noncontact athletes during the off-season (lost participants included athletes who were no longer on the team or had new MRI exclusions).

\section{Clinical results}

\section{Contact vs noncontact}

Off-season noncontact athletes had on average more SCAT3 self-reported symptoms (mean 4.26 [SD 4.12]) with greater severity $(6.87[8.00])$ compared to the other 3 groups of participants (i.e., in- and off-season contact and in-season noncontact), who reported $\leq 2$ symptoms with severity $\leq 3$ ( $F$ $>4.0, p<0.01$ ).

\section{Pair-wise changes}

Pair-wise analysis (i.e., within participant) included concussion-free athletes with both in- and off-season data (60 contact and 23 noncontact athletes). There was an increase in immediate memory $(14.33[1.32]$ to 14.72 [0.56], 95\% confidence interval $[\mathrm{CI}] 0.09-0.70, p=0.01)$ and concentration (3.07 [0.86] to 3.47 [0.75], 95\% CI 0.14-0.66, $p=0.003$ ) composite scores for off-season contact athletes compared to their own in-season data, but there were no significant changes for noncontact athletes.

\section{Accelerometer results}

Only concussion-free athletes who experienced at least 1 impact (defined as $\geq 15 g$ ) during practice or game play were included for statistical analysis. Twenty-six rugby players met this inclusion criterion, while 9 rowers and 11 rugby players did not. All impact measures failed the Shapiro-Wilks test of normality $(p<0.05)$, so nonparametric descriptors were used and are described in table 2.

\section{DTI results}

\section{Contact vs noncontact}

There were significant differences across all diffusion metrics within the white matter skeleton when concussion-free contact athletes were compared to noncontact athletes (figure 1). Diffusion changes were located along the corpus callosum, cingulum, and brainstem, as well as portions of other long white matter tracts, including the superior longitudinal and inferior occipital fasciculi. An ROI analysis was performed including 4 regions: inferior portions of white matter tracts within the brainstem (figure $1 \mathrm{E}$ ) and 3 sections of the corpus callosum (genu, splenium, and body) constrained to the FAderived skeleton. Results of the linear mixed-effects model for these $\mathrm{ROI}$ are given in table 3 . The $\mathrm{MD}$ and $\mathrm{AD}$ values of the splenium and genu subsections of the corpus callosum had a significant effect of group in which $\mathrm{AD}$ was higher in the contact athletes compared to noncontact athletes and $\mathrm{MD}$ was higher in contact athletes compared to in-season noncontact athletes. The $\mathrm{MD}, \mathrm{AD}$, and $\mathrm{RD}$ values of the body of the corpus callosum had a significant group-by-time interaction, as well as main effects for group and time. $\mathrm{MD}, \mathrm{RD}$, and $\mathrm{AD}$ were all higher $(p<0.001)$ in both in- and off-season for contact compared to in-season noncontact data only (and compared to off-season noncontact for $\mathrm{AD}$ values only, representing a meaningful main effect for group in the presence of the significant group-by-time interaction; although other diffusion measures were close to significantly different compared to off-season noncontact data as well $[p<0.01]$, they did not survive statistical correction, hence the significant group-by-time interaction). $\mathrm{AD}$ within the brainstem had a significant main effect of time. However, only contact athletes changed significantly between the in-season and offseason $(p<0.001)$. The FA in the brainstem was significantly associated with the SCAT immediate memory subtest scores $(t=-2.3, p=0.03)$.

\section{Pair-wise changes}

The brainstem ROI had lower FA (0.619 [0.0253] vs 0.603 [0.0254], 95\% CI 0.022-0.009) and higher MD $\left(0.67 \times 10^{-3}\right.$ $\left[3.1 \times 10^{-5}\right]$ vs $0.70 \times 10^{-3}\left[3.5 \times 10^{-5}\right] \mathrm{mm}^{2} / \mathrm{s}, 95 \% \mathrm{CI} 2.7 \times$ $\left.10^{-5}-4.8 \times 10^{-5}\right), \mathrm{AD}\left(1.2 \times 10^{-3}\left[4.9 \times 10^{-5}\right]\right.$ vs $1.3 \times 10^{-3}$ $\left.\left[5.2 \times 10^{-5}\right] \mathrm{mm}^{2} / \mathrm{s}, 95 \% \mathrm{CI} 3.6 \times 10^{-5}-6.8 \times 10^{-5}\right)$, and $\mathrm{RD}$ $\left(0.41 \times 10^{-3}\left[2.9 \times 10^{-5}\right]\right.$ vs $0.44 \times 10^{-3}\left[3.2 \times 10^{-5}\right] \mathrm{mm}^{2} / \mathrm{s}$, $95 \%$ CI $2.0 \times 10^{-5}-3.9 \times 10^{-5}$ ) for concussion-free contact 
Table 2 Head impact sensor data

\begin{tabular}{llllll}
\hline $\begin{array}{l}\text { Rugby head } \\
\text { impacts }\end{array}$ & $\begin{array}{l}\text { No. of impacts } \\
\text { exceeding 15g }\end{array}$ & $\begin{array}{l}\text { Peak linear acceleration, } \\
\text { median (IQR), } \mathbf{g}\end{array}$ & $\begin{array}{l}\text { HIC }_{15}, \\
\text { median } \\
\text { (IQR) }\end{array}$ & $\begin{array}{l}\text { Peak rotational velocity, } \\
\text { median (IQR), } / \mathbf{s}\end{array}$ & $\begin{array}{l}\text { Average no. of impacts } \\
\text { per athlete (IQR) }\end{array}$ \\
\hline Total & 151 & $25.05(19.10-31.72)$ & $\begin{array}{l}8.9 \\
(4.30-14.40)\end{array}$ & $1,286.00(895.50-2,260.50)$ & $3(1-6)$ \\
\hline $\begin{array}{l}\text { Impacts during } 2 \\
\text { practices }\end{array}$ & 115 & $26.05(19.89-31.98)$ & $\begin{array}{l}8.70 \\
(3.90-13.40)\end{array}$ & $1,293.00(889.50-2,307.00)$ & $2(1-6)$ \\
\hline $\begin{array}{l}\text { Impacts during } \\
\text { game }\end{array}$ & 36 & $23.07(18.69-27.22)$ & $\begin{array}{l}10.95 \\
(5.85-18.10)\end{array}$ & $1,230.50(908.25-1867.50)$ & $1(0-2)$ \\
\hline
\end{tabular}

Abbreviations: $\mathrm{HIC}_{15}=$ head injury criteria, i.e., the maximum exponentially weighted integral within a 15-millisecond window of time; IQR = interquartile range.

Rugby players who experienced at least 1 impact exceeding $15 \mathrm{~g}$ during 2 monitored contact practices and 1 game are included.

athletes during the off-season compared to their own data during the in-season $(p<0.001)$. There were no significant changes between the in- and off-season for other ROIs or in the noncontact athletes (figure 2).

\section{Longitudinal data and concussion history}

For the subset of rugby players with 2 years of concussion-free data $(\mathrm{n}=12)$, there were significant repeated-measure changes in all diffusion measures over time within the brainstem $\mathrm{ROI}$ (figure 2). The $\mathrm{AD}$ within the genu of the corpus callosum $\left(1.67 \times 10^{-3}\left[7.6 \times 10^{-5}\right]\right.$ vs $1.7 \times 10^{-3}\left[6.9 \times 10^{-5}\right]$ $\mathrm{mm}^{2} / \mathrm{s}, 95 \%$ CI $\left.5.6 \times 10^{-5}-5.0 \times 10^{-5}, p=0.02\right)$ and the splenium $\left(1.71 \times 10^{-3}\left[6.3 \times 10^{-5}\right]\right.$ vs $1.74 \times 10^{-3}\left[5.5 \times 10^{-5}\right]$ $\mathrm{mm}^{2} / \mathrm{s}, 95 \%$ CI $\left.4.3 \times 10^{-5}-1.6 \times 10^{-5}, p=0.03\right)$ was significantly lower for contact athletes with a previous concussion history compared to those without.

\section{rs-fMRI results}

\section{Contact vs noncontact}

Concussion-free contact athletes during both the in- and offseason had greater connectivity between the DMN and the posterior cingulate cortex (PCC) compared to in- and offseason noncontact $(p<0.01$, figure 3$)$. Connectivity between the lateral visual network and areas throughout the occipital lobe was increased for in- and off-season contact athletes compared to in-season noncontact athletes. There were no significant differences in functional connectivity in the cerebellar RSN after correction for multiple comparisons ( $p$ $>0.01$ ).

\section{Pair-wise changes}

Within the PCC ROI (5-mm radius sphere), there were no significant pair-wise differences between the in- and offseason for contact or noncontact athletes. Therefore, data collected from contact athletes across 2 years were not explored further.

\section{Concussion history}

There were no significant differences in connectivity strength between the PCC and DMN when rugby athletes with and without a concussion history were compared $(p=0.8)$.

\section{Relationship between DTI and rs- fMRI measures}

There was a significant correlation between the $\mathrm{AD}$ within the splenium of the corpus callosum and the DMN connectivity strength with the PCC in contact athletes $(r=-0.32$, $p=0.0002$, figure $3 \mathrm{~F})$ but not in noncontact athletes $(r=0.020$, $p=0.9)$.

\section{Discussion}

In this study of female varsity athletes, we identified several differences in clinical, head impact, DTI, and rs-fMRI data collected from athletes participating in contact sports compared to athletes in noncontact sports. Notably, this was in the absence of a diagnosed concussion or symptoms within the 6-month period before or during the study. DTI was used to detect extensive alterations throughout the white matter in contact compared to noncontact athletes, including the cingulum and corpus callosum, as well as the white matter within deep brain structures such as the brainstem. With these changes in microstructure, we expected, and found, changes in rs-fMRI connectivity in structurally and functionally related regions within the DMN and laminar visual network in contact compared to noncontact athletes.

Rugby players experience subclinical impacts and rotations in practice and game play. A previous study of amateur male rugby players reported 77 head impacts exceeding $10 \mathrm{~g}$ acceleration per player per game with exceptionally fast rotational accelerations. ${ }^{16} \mathrm{~A}$ more recent study of female rugby players found on average 14 head impacts $(>10 g)$ per player per game. ${ }^{17}$ The rugby team studied here participated in a training camp where they experienced subclinical impacts during multiple daily practices and weekly games as they endeavored to make the team. Some athletes may also participate in summer rugby leagues, so the in-season data likely reflect effects accrued due to several consecutive months of high-impact activity even though the data were acquired relatively early in their season. The devices used in 


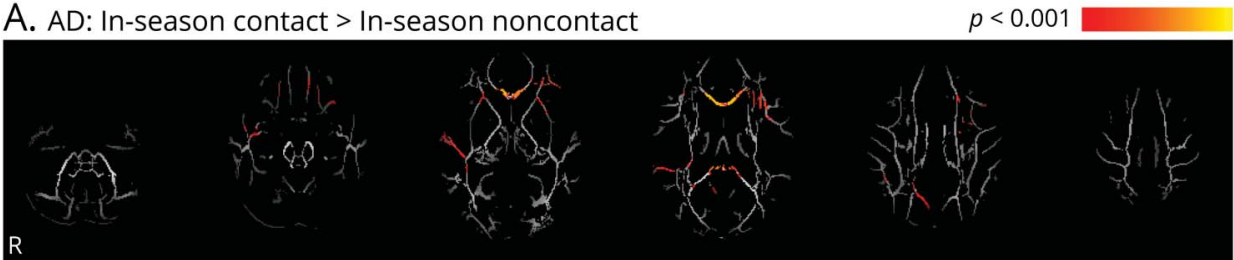

B. MD: Off-season contact $>$ In-season noncontact

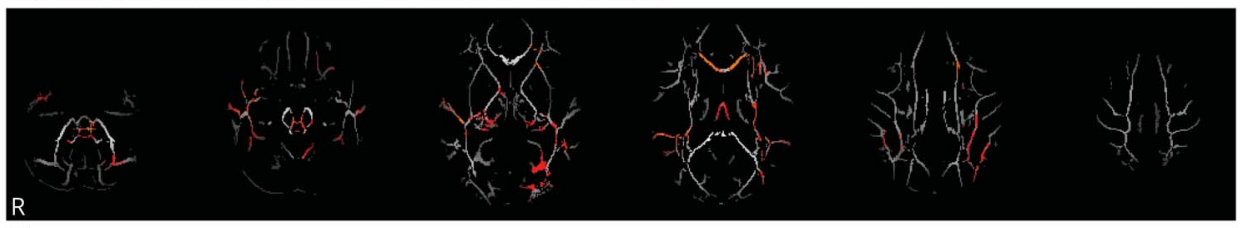

C. FA: In-season noncontact $>$ Off-season contact

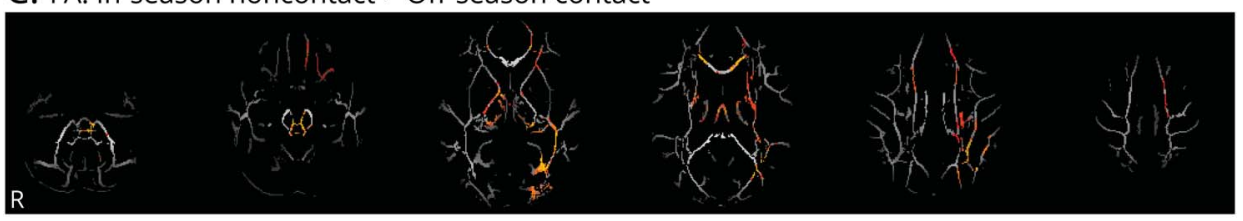

D. RD: In-season contact $>$ In-season noncontact

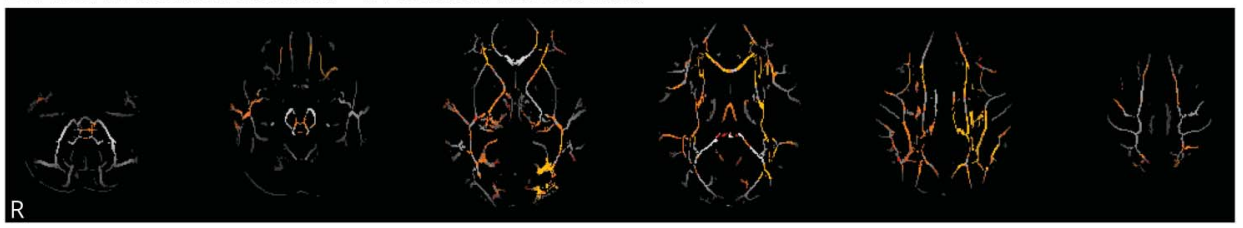

E. AD: Off-season contact $>$ In-season contact $(p<0.05)$

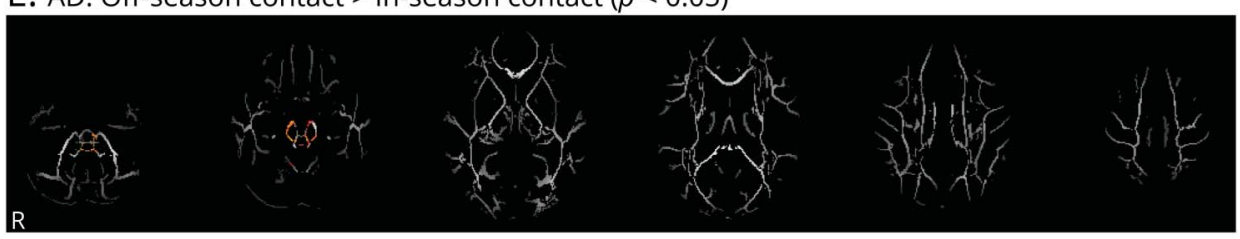

(A-E) Statistically significant white matter axial diffusivity (AD), mean diffusivity (MD), radial diffusivity (RD), and fractional anisotropy (FA) differences between contact athletes (during both the in- and off-season) and noncontact athletes during the in-season are shown in hot colors, including areas of the corpus callosum, cingulum, brainstem, superior longitudinal, and inferior occipital fasciculi $(p<0.001$ unless otherwise indicated). this study had a higher threshold of $15 \mathrm{~g}$. However, $45 \%$ of head impacts may have magnitudes between $10 \mathrm{~g}$ and $15 \mathrm{~g} .{ }^{18}$ During a single practice, the rowers did not experience any impacts, while $70 \%$ (26 of 37 ) of the monitored rugby players experienced at least 1 impact $(>15 g)$ during 2 practices and 1 preseason game. Subclinical impacts accumulate throughout a full season and over years of participation in contact sport.

In vivo studies of maximal shear and strain forces exerted on the human brain have shown that frontal lobe regions, the brainstem, and tracts that border the gray matter experience the greatest forces, even with very low rotational motion. ${ }^{19}$ Previous MRI studies suggest that changes in white matter diffusion properties are directly related to the number of impacts $^{8,20,21}$ and are not observed in noncontact sports such as track, rowing, and skiing, ${ }^{11}$ which is in agreement with our results.

Clinically, noncontact athletes reported more symptoms with higher severity compared to the rugby players, despite the absence of concussion. This surprising finding demonstrates the challenges of using subjective self-reported symptoms to diagnose and monitor athletes with the SCAT3 test. Noncontact athletes may not have completed SCAT3 examinations before enrolling in this study. Therefore, an exposure effect could be driving the difference between the groups of athletes. The symptoms reported could also relate to other factors such as lack of sleep, stress, alcohol use, or the long season and the accumulation of fatigue and muscle strain, particularly for the swimmers, who were assessed very shortly after the season ended. Nonetheless, pair-wise improvements in immediate memory and concentration composite scores between the in- and off-season in contact athletes may reflect neurocognitive improvements during a relative break from contact practices and play during the off-season training period.

Changes in MR spectroscopy have previously been reported in a subset of these rugby players; glutamine concentrations were reduced after concussion and during the off-season and may relate to an evolving shift in 
Table 3 Linear mixed-effects model results

\begin{tabular}{|c|c|c|}
\hline Metric within ROI & Effect & $p$ Value \\
\hline Brainstem MD & Time & 0.003 \\
\hline \multirow[t]{3}{*}{ Brainstem AD } & Time & $0.00004^{a}$ \\
\hline & Time $\times$ group & 0.003 \\
\hline & Group & 0.02 \\
\hline \multirow[t]{3}{*}{ Splenium MD } & Time & 0.04 \\
\hline & Time $\times$ group & 0.008 \\
\hline & Group & $0.001^{a}$ \\
\hline \multirow[t]{2}{*}{ Splenium AD } & Group & $0.0009^{a}$ \\
\hline & Time $\times$ group & 0.04 \\
\hline Splenium FA & Group & 0.02 \\
\hline \multirow[t]{3}{*}{ Splenium RD } & Time & 0.03 \\
\hline & Time $\times$ group & 0.005 \\
\hline & Group & 0.01 \\
\hline Genu MD & Group & 0.01 \\
\hline Genu AD & Group & $0.0001^{a}$ \\
\hline \multirow[t]{3}{*}{ Body MD } & Time & $0.002^{a}$ \\
\hline & Time $\times$ group & $0.0002^{\mathrm{a}}$ \\
\hline & Group & $0.00009^{a}$ \\
\hline \multirow[t]{3}{*}{ Body AD } & Time & $0.0007^{a}$ \\
\hline & Time $\times$ group & $0.0002^{\mathrm{a}}$ \\
\hline & Group & $0.000001^{\circ}$ \\
\hline \multirow[t]{3}{*}{ Body RD } & Time & 0.005 \\
\hline & Time $\times$ group & $0.0006^{a}$ \\
\hline & Group & $0.002^{\mathrm{a}}$ \\
\hline DMN and PCC connectivity ( $z$ statistic) & Group & $0.001^{a}$ \\
\hline
\end{tabular}

Abbreviations: $A D=$ axial diffusion; $D M N=$ default mode network; $F A=$ fractional anisotropy; $M D=$ mean diffusion; $R D=$ radial diffusion; $P C C=$ posterior cingulate cortex; $\mathrm{ROI}=$ region of interest.

The effect of time (i.e., in- and off-season) and group (i.e., contact and noncontact) and the interaction between time and group on diffusion metrics within the brainstem and 3 subregions of the corpus callosum and connectivity strength between the DMN and the PCC. Participant number was set as a random factor, and the number of self-reported previous concussions, age at the time of the scan, and Sports Concussion Assessment Tool immediate memory and concentration subtest scores were used as potential predictors.

${ }^{a}$ Effects that survive Bonferroni correction $(p<0.003)$.

oxidative metabolism or microglial priming. ${ }^{13}$ All diffusion measures within the brainstem changed significantly between the in- and off-season in contact athletes only. The FA within the brainstem was significantly related to SCAT immediate memory scores, suggesting that these pair-wise changes in brain microstructural measures are related to exposure to repetitive impacts and altered immediate memory capacity.

In this study, we found distinct increases in $\mathrm{MD}, \mathrm{RD}$, and $\mathrm{AD}$ and decreased FA, some of which overlapped in the same white matter regions (including portions of the corpus callosum) in general when concussion-free contact and noncontact athletes were compared. This provides further evidence of long-lasting or cumulative changes in the microstructure of the brain due to years of contact play. These widespread diffusion changes may represent neuroinflammatory processes. However, given that fluctuations between the in- and off-season were observed only in white matter within the brainstem, alterations in myelin, microstructure, microglial priming, or water content are more likely. This may be a compensatory response to the repetitive 


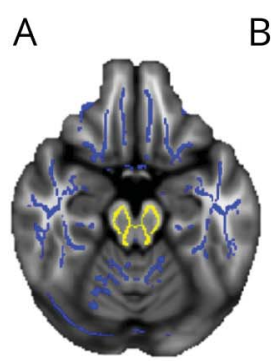

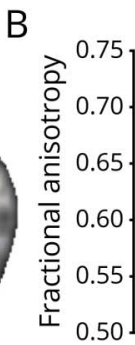

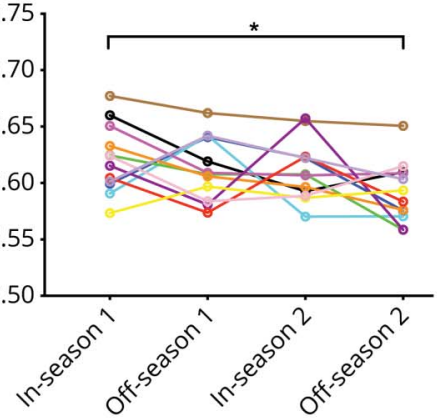

Contact athletes
C

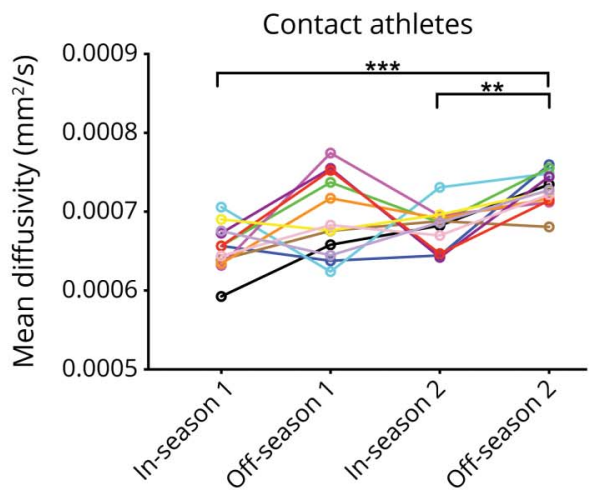

D

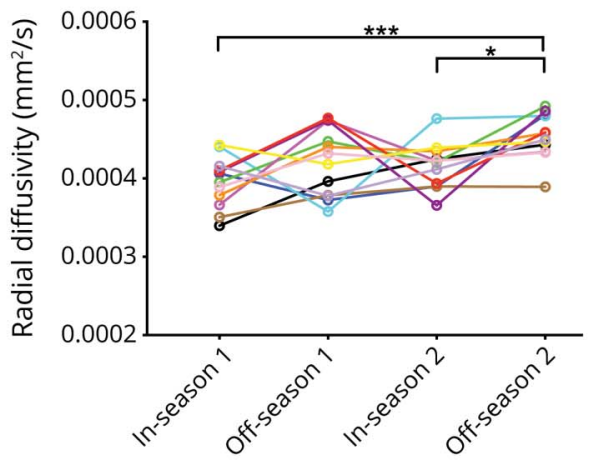

$\mathrm{E}$

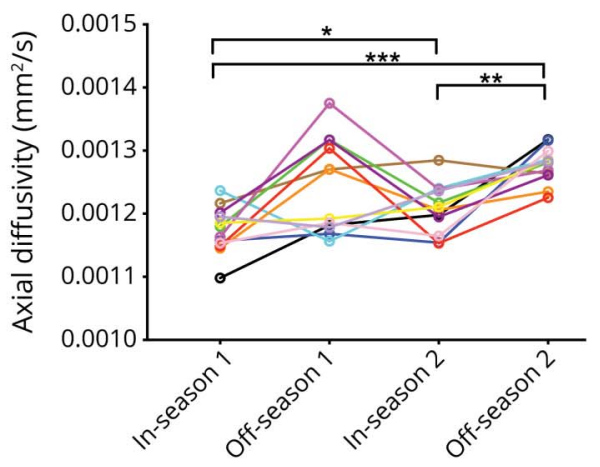

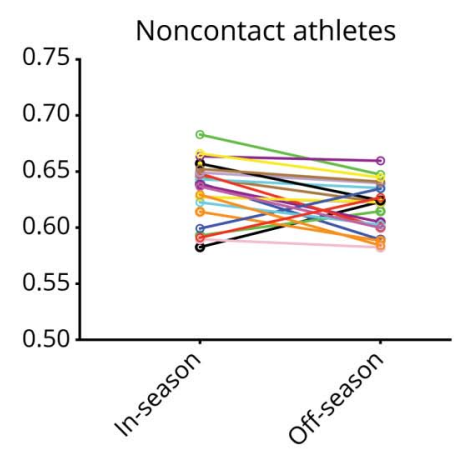

Non-contact athletes
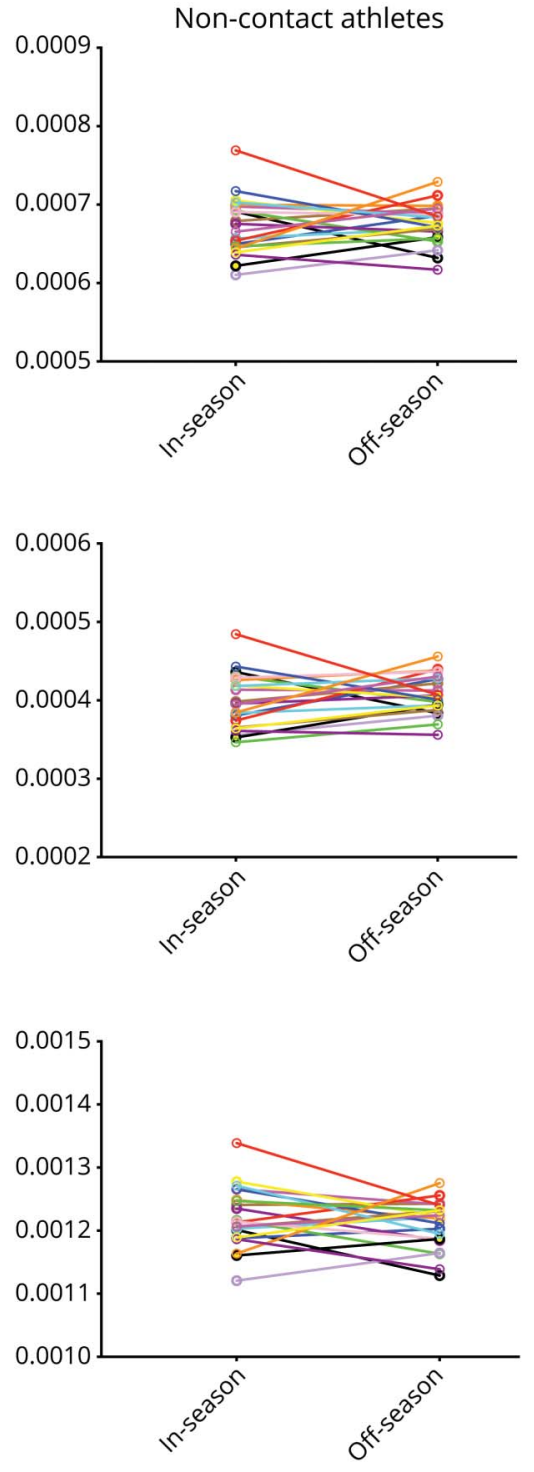

Longitudinal changes in (B) fractional anisotropy (FA), (C) mean diffusivity, (D) axial diffusivity, and (E) radial diffusivity in contact and noncontact athletes over 2 or 1 season, respectively, within the brainstem region of interest shown in (A) yellow with the FA skeleton in blue. Each colored line connects data from an individual athlete over time, and significant repeated measures are indicated $\left({ }^{*} p<0.05,{ }^{* *} p<0.01, * \star * p<\right.$ $0.001)$.

impacts experienced through training and competition, which continues to progress over years of play. Another possibility is the presence of neurodegenerative processes in these relatively young athletes, ${ }^{22}$ resulting in accelerated age-related changes in white matter diffusion properties. ${ }^{23}$ Only a subset of $\mathrm{AD}$ changes within the corpus callosum were related to a history of concussion and may reflect long-term axonal disruption or damage. These possible explanations may not be exclusive; certain brain regions exhibit distinct changes related to the distribution of forces throughout the brain. Average group differences represent a distribution of data in which some contact athletes may be within normal, noncontact 


\section{A. In-season contact}

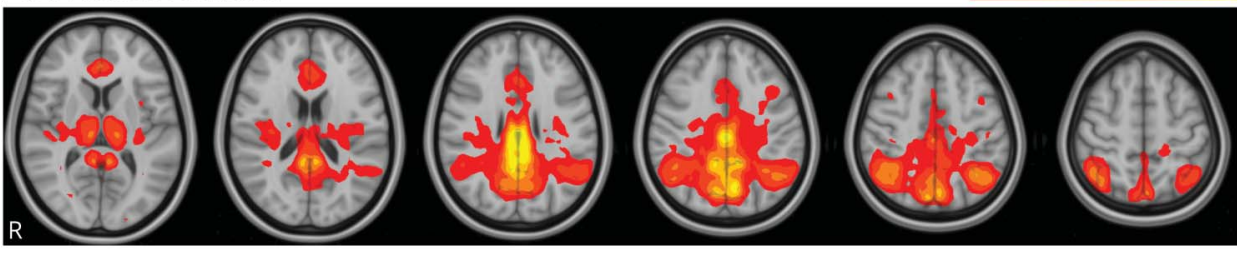

B. Off-season contact

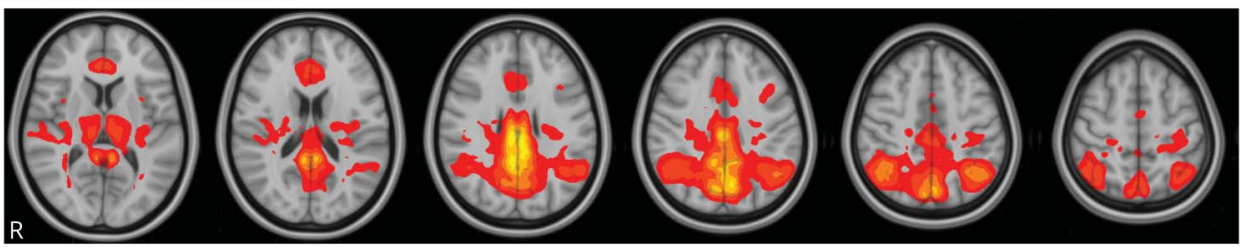

C. In-season noncontact

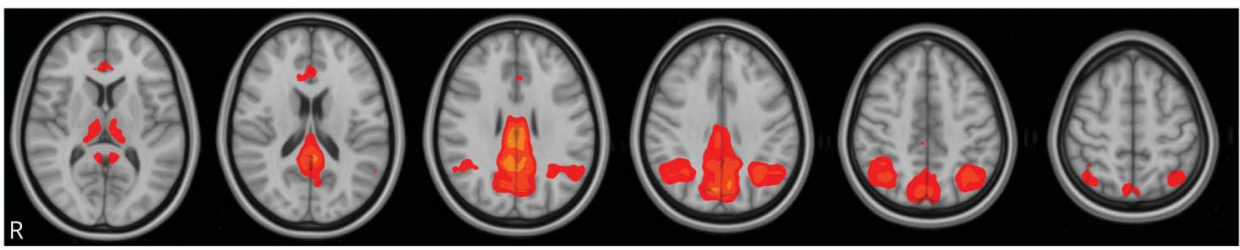

D. Off-season noncontact

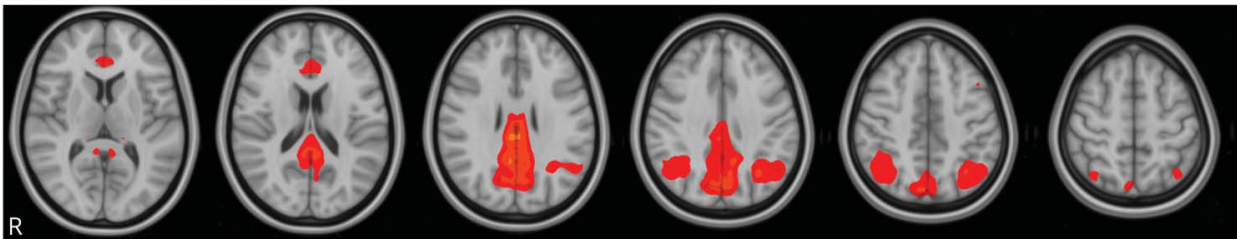

E. PCC significant region

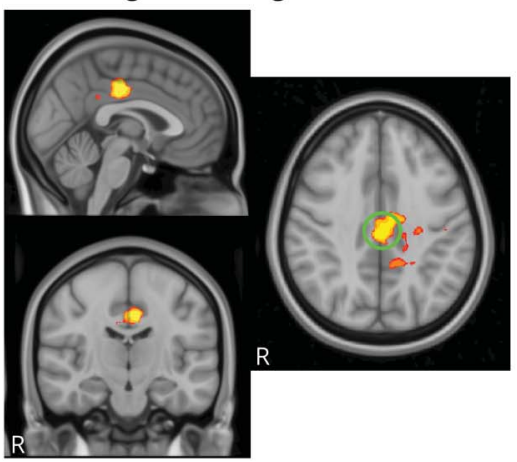

F. Correlation between DTI and rs-fMRI

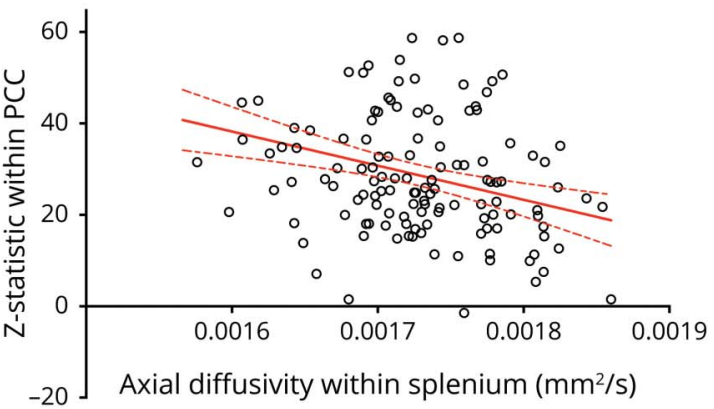

(A-D) Average default mode network (DMN) for each group of participants in which hot colors indicate regions that have high functional connectivity. (E) Contact athletes had significantly higher $(p<0.01)$ functional connectivity compared to noncontact athletes, with a green circle indicating the posterior cingulate cortex $(\mathrm{PCC}$ ) region of interest. (F) Significant correlation between DMN connectivity strength ( $z$ statistic) with the PCC and the axial diffusion within the splenium of the corpus callosum in contact athletes only $(r=-0.32, p=0.0002)$. DTI $=$ diffusion tensor imaging; rs-fMRI = resting-state fMRI. ranges and a subset may exhibit substantial microstructural alterations. This is consistent with more detailed studies of neurologic performance showing that athletes could be separated into 3 categories: concussed athletes with symptoms and cognitive impairment, and nonconcussed athletes with and without cognitive impairment despite lack of symptoms. ${ }^{7}$

Studies focusing on DTI changes of concussion are severity and time dependent, with some studies observing conflicting directions of change. Previous studies focusing on more severe models of traumatic brain injury have reported decreases in FA in areas such as the corpus callosum, possibly due to disruption of axonal structure and demyelination. ${ }^{24}$ Other studies of concussion report an increase in FA and a decrease in $\mathrm{MD},{ }^{21,25-27}$ and many compare concussed athletes to a control group of healthy contact sport athletes without regard or specification of the scan time relative to the season. ${ }^{25,28-30}$ Although factors such as image acquisition and analyses methods could contribute to the variability of magnetic resonance results, our results suggest that the common use of contact athlete control groups exposed to subclinical impacts over years of play may contribute to the lack of consensus in the literature on the direction and interpretation of changing DTI metrics and connectivity after concussion. 
Increased MD and decreased FA have also been reported in previous studies of nonconcussed football and hockey players, ${ }^{11}$ and increased $\mathrm{RD}$ and $\mathrm{AD}$ were reported in the corpus callosum of male soccer players compared to noncontact swimmers (with no changes in MD or FA). ${ }^{31}$ There may also be sex-related differences in how the brain responds to repetitive sports-related impacts. A recent study examining nonconcussed female and male hockey players before and after the season observed that female athletes had significant decreases in $F A$ and increases in $M D, R D$, and $A D$, while male athletes showed no changes. ${ }^{32}$ Here, we replicated those findings in female athletes but only within the brainstem; in addition, we demonstrated progressive changes over 2 seasons of contact play. We were able to expand on these results by comparing to a control group of age-matched, female noncontact athletes to show that changes in diffusion between the in- and off-season were present only in contact athletes and were not due to periods of high-intensity exercise.

Resting-state hyperconnectivity patterns have been found after concussion ${ }^{33}$ and during the season in contact athletes compared to noncontact controls. ${ }^{8}$ Similar to our study, regional hyperconnectivity with the DMN suggests a long-term effect from years of play. DMN connectivity with the PCC was significantly and spatially related to AD within the splenium of the corpus callosum for contact athletes only. Hyperconnectivity may be a compensatory mechanism to recruit widespread regions to continue execution of normal function or regulation during periods of exposure to repetitive sport-related impacts and the consequent disruption of underlying axonal integrity. Of course, rs-fMRI is sensitive to blood oxygenation and volume changes. Therefore, neurovascular coupling and altered cerebral blood flow could also be responsible for these effects. ${ }^{34}$

Rowers and swimmers did not have a history of concussion, and coaches closely monitored the rugby cohort for concussions. However, previous concussions may still have a nonuniform effect on MRI measures. We previously reported both acute and persistent decreases in MD and $\mathrm{AD}$ and increased FA in a subset of concussed rugby players within the inferior portions of the brainstem and the corpus callosum, respectively. ${ }^{14}$ Here, we report that the $\mathrm{AD}$ within the genu and splenium of the corpus callosum was significantly lower in contact athletes with a concussion history compared to those without a concussion history. Given that we also found that contact athletes in general had increased diffusivities compared to noncontact athletes, the diffusion changes we observed in contact athletes may indeed reflect compensatory processes that are offset from normal due to a history of concussion. This could be a neurobiological reason why athletes with a concussion history may be more vulnerable to injury and why subsequent concussions often involve more serious or longlasting symptoms. ${ }^{35,36}$
Despite these interesting findings, there are some limitations of this study that are important to consider. While the rugby athletes included here did not experience a diagnosed concussion, there may be undiagnosed concussions that went unnoticed by the coaching staff and peers. Our longitudinal control group provided a solid study design to evaluate changes related to subclinical impacts. However, we could not directly correlate to the number of impacts or accelerometerderived metrics of these impacts because official university athletic conference rules do not allow the head sensors to be worn.

While the collective physiologic interpretation of these changes is complex, the nature of repetitive impacts experienced by these female rugby players clearly affects multiparametric imaging measures across both single and multiple seasons of contact play, even in the absence of concussion. Our observations may reflect ongoing neuroprotective or compensatory mechanisms that help protect the brain from injury and damage due to contact sport. If the brain exhausts this potential ability to protect itself through long-term exposure to repetitive impacts or concussions, is it more susceptible to concussion and at risk of neurodegenerative processes later in life? Combined animal imaging and histologic studies that model repetitive subclinical impacts may aid in understanding the specific changes in brain physiology that underlie the diffusion and functional connectivity changes we report here. However, on the basis of these findings, future studies of concussion that compare to control groups of contact athletes need to incorporate concussion history and quantify sports-related subclinical impacts because we have shown that they have both transient and progressive effects on brain microstructure and function.

\section{Acknowledgment}

High-quality imaging data were acquired thanks to the staff at the Centre for Functional and Metabolic Mapping. The authors thank the Western University female rugby players, rowers, and swimmers for their willingness to participate in this longitudinal study and for the excellent support provided by the coaches and team physicians.

\section{Study funding}

Funded through the Schulich School of Medicine and Dentistry (A.B. and G.A.D.), Western University; the Canadian Institutes for Health Research (R.S.M.); Brain Canada (R.S.M.); Canada First Research Excellence Fund; and the Natural Sciences and Engineering Research Council of Canada (K.Y.M.).

\section{Disclosure}

The authors report no disclosures relevant to the manuscript. Go to Neurology.org/N for full disclosures.

\section{Publication history}

Received by Neurology August 27, 2019. Accepted in final form January 5, 2020. 
Appendix Authors

\begin{tabular}{|c|c|c|}
\hline Name & Location & Contribution \\
\hline $\begin{array}{l}\text { Kathryn Y. } \\
\text { Manning, } \\
\text { PhD }\end{array}$ & $\begin{array}{l}\text { Western University, } \\
\text { London, Canada }\end{array}$ & $\begin{array}{l}\text { Drafting the manuscript, } \\
\text { analysis and interpretation of } \\
\text { data, statistical analysis }\end{array}$ \\
\hline $\begin{array}{l}\text { Jeffrey S. } \\
\text { Brooks, MSc }\end{array}$ & $\begin{array}{l}\text { Western University, } \\
\text { London, Canada }\end{array}$ & Analysis of the data \\
\hline $\begin{array}{l}\text { James P. } \\
\text { Dickey, PhD }\end{array}$ & $\begin{array}{l}\text { Western University, } \\
\text { London, Canada }\end{array}$ & $\begin{array}{l}\text { Major role in the acquisition of } \\
\text { data }\end{array}$ \\
\hline $\begin{array}{l}\text { Alexandra } \\
\text { Harriss, MSc }\end{array}$ & $\begin{array}{l}\text { Western University, } \\
\text { London, Canada }\end{array}$ & Analysis of the data \\
\hline $\begin{array}{l}\text { Lisa Fischer, } \\
\text { MD }\end{array}$ & $\begin{array}{l}\text { Fowler Kennedy Sport } \\
\text { Medicine, London, } \\
\text { Ontario, Canada }\end{array}$ & $\begin{array}{l}\text { Design and conceptualization } \\
\text { of the study }\end{array}$ \\
\hline $\begin{array}{l}\text { Tatiana } \\
\text { Jevremovic, } \\
\text { MD }\end{array}$ & $\begin{array}{l}\text { Fowler Kennedy Sport } \\
\text { Medicine, London, } \\
\text { Ontario, Canada }\end{array}$ & $\begin{array}{l}\text { Major role in the acquisition of } \\
\text { data }\end{array}$ \\
\hline $\begin{array}{l}\text { Kevin } \\
\text { Blackney, } \\
\text { MSc }\end{array}$ & $\begin{array}{l}\text { Western University, } \\
\text { London, Canada }\end{array}$ & $\begin{array}{l}\text { Major role in the acquisition of } \\
\text { data }\end{array}$ \\
\hline $\begin{array}{l}\text { Christy } \\
\text { Barreira, } \\
\text { BSc }\end{array}$ & $\begin{array}{l}\text { Robarts Research } \\
\text { Institute, London, } \\
\text { Ontario, Canada }\end{array}$ & $\begin{array}{l}\text { Major role in the acquisition of } \\
\text { data }\end{array}$ \\
\hline $\begin{array}{l}\text { Arthur } \\
\text { Brown, PhD }\end{array}$ & $\begin{array}{l}\text { Western University, } \\
\text { London, Canada }\end{array}$ & $\begin{array}{l}\text { Design and conceptualization } \\
\text { of the study }\end{array}$ \\
\hline $\begin{array}{l}\text { Robert } \\
\text { Bartha, PhD }\end{array}$ & $\begin{array}{l}\text { Western University, } \\
\text { London, Canada }\end{array}$ & $\begin{array}{l}\text { Design and conceptualization } \\
\text { of the study }\end{array}$ \\
\hline $\begin{array}{l}\text { Tim } \\
\text { Doherty, } \\
\text { MD, PhD }\end{array}$ & $\begin{array}{l}\text { Western University, } \\
\text { London, Canada }\end{array}$ & $\begin{array}{l}\text { Design and conceptualization } \\
\text { of the study }\end{array}$ \\
\hline $\begin{array}{l}\text { Douglas } \\
\text { Fraser, MD, } \\
\text { PhD }\end{array}$ & $\begin{array}{l}\text { London Health Sciences } \\
\text { Centre, London, } \\
\text { Ontario, Canada }\end{array}$ & $\begin{array}{l}\text { Design and conceptualization } \\
\text { of the study }\end{array}$ \\
\hline $\begin{array}{l}\text { Jeff Holmes, } \\
\text { PhD }\end{array}$ & $\begin{array}{l}\text { Western University, } \\
\text { London, Canada }\end{array}$ & $\begin{array}{l}\text { Design and conceptualization } \\
\text { of the study }\end{array}$ \\
\hline $\begin{array}{l}\text { Gregory A. } \\
\text { Dekaban, } \\
\text { PhD }\end{array}$ & $\begin{array}{l}\text { Western University, } \\
\text { London, Canada }\end{array}$ & $\begin{array}{l}\text { Design and conceptualization } \\
\text { of the study }\end{array}$ \\
\hline $\begin{array}{l}\text { Ravi S. } \\
\text { Menon, PhD }\end{array}$ & $\begin{array}{l}\text { Western University, } \\
\text { London, Canada }\end{array}$ & $\begin{array}{l}\text { Design and conceptualization } \\
\text { of the study, image } \\
\text { acquisition, design and } \\
\text { interpretation of data }\end{array}$ \\
\hline
\end{tabular}

\section{References}

1. Breedlove KM, Breedlove EL, Robinson M, et al. Detecting neurocognitive and neurophysiological changes as a result of subconcussive blows among high school football athletes. Athl Train Sport Heal Care 2014;6:119-127.

2. Shuttleworth-Edwards AB, Smith I, Radloff SE. Neurocognitive vulnerability amongst university rugby players versus noncontact sport controls. J Clin Exp Neuropsychol 2008;30:870-884.

3. Killam C, Cautin RL, Santucci AC. Assessing the enduring residual neuropsychological effects of head trauma in college athletes who participate in contact sports. Arch Clin Neuropsychol 2005;20:599-611.

4. Miller JR, Adamson GJ, Pink MM, Sweet JC. Comparison of preseason, midseason, and postseason neurocognitive scores in uninjured collegiate football players. Am J Sports Med 2007;35:1284-1288.

5. Alosco ML, Kasimis AB, Stamm JM, et al. Age of first exposure to American football and long-term neuropsychiatric and cognitive outcomes. Transl Psychiatry 2017;7: e1236.

6. McAllister TW, Flashman LA, Maerlender A, et al. Cognitive effects of one season of head impacts in a cohort of collegiate contact sport athletes-with comments. Neurology 2012;78:1777-1784.
7. Talavage TM, Nauman E, Breedlove EL, et al. Functionally-detected cognitive impairment in high school football players without clinically-diagnosed concussion. J Neurotrauma 2010;31:327-338.

8. Abbas K, Shenk TE, Poole VN, et al. Alteration of default mode network in high school football athletes due to repetitive subconcussive mild traumatic brain injury: a resting-state functional magnetic resonance imaging study. Brain Connect 2015;5: 91-101.

9. Stamm JM, Koerte IK, Muehlmann M, et al. Age at first exposure to football is associated with altered corpus callosum white matter microstructure in former professional football players. J Neurotrauma 2015;32:1768-1776.

10. Koerte IK, Kaufmann D, Hartl E, et al. A prospective study of physician-observed concussion during a varsity university hockey season: white matter integrity in ice hockey players: part 3 of 4. Neurosurg Focus 2012;33:1-7.

11. McAllister TW, Ford JC, Flashman LA, et al. Effect of head impacts on diffusivity measures in a cohort of collegiate contact sport athletes. Neurology 2014;82:63-69.

12. SCAT3. Br J Sport Med 2013;47:259.

13. Schranz AL, Manning KY, Dekaban GA, et al. Reduced brain glutamine in female varsity rugby athletes after concussion and in non-concussed athletes after a season of play. Hum Brain Mapp 2018;39:1489-1499.

14. Manning KY, Llera A, Dekaban GA, et al. Linked MRI signatures of the brain's acute and persistent response to concussion in female varsity rugby players. Neuroimage Clin 2019;21:101627.

15. Smith SM, Fox PT, Miller KL, et al. Correspondence of the brain's functional architecture during activation and rest. Proc Natl Acad Sci USA 2009;106: 13040-13045.

16. King DA, Hume PA, Brughelli M, Gissane C. Instrumented mouthguard acceleration analyses for head impacts in amateur rugby union players over a season of matches. Am J Sport Med 2015;43:614-624.

17. King DA, Hume PA, Gissane C, Kieser DC, Clark TN. Head impact exposure from match participation in women's rugby league over one season of domestic competition. J Sci Med Sport 2018;21:139-146.

18. King D, Hume P, Gissane C, Brughelli M, Clark T. The influence of head impact threshold for reporting data in contact and collision sports: systematic review and original data analysis. Sport Med 2016;46:151-169.

19. Bayly PV, Cohen TS, Leister EP, Ajo D, Leuthardt EC, Genin GM. Deformation of the human brain induced by mild acceleration. J Neurotrauma 2005;22:845-856.

20. Davenport EM, Whitlow CT, Urban JE, et al. Abnormal white matter integrity related to head impact exposure in a season of high school varsity football. J Neurotrauma 2014;8:1-32.

21. Bazarian JJ, Zhu T, Blyth B, Borrino A, Zhong J. Subject-specific changes in brain white matter on diffusion tensor imaging after sports-related concussion. Magn Reson Imaging 2012;30:171-180.

22. Mez J, Daneshvar DH, Kiernan PT, et al. Clinicopathological evaluation of chronic traumatic encephalopathy in players of American football. JAMA 2017;318:360-370.

23. Sexton $\mathrm{CE}$, Walhovd $\mathrm{KB}$, Storsve $\mathrm{AB}$, et al. Accelerated changes in white matter microstructure during aging: a longitudinal diffusion tensor imaging study. J Neurosci 2014;34:15425-15436

24. Kraus MF, Susmaras T, Caughlin BP, Walker CJ, Sweeney JA, Little DM. White matter integrity and cognition in chronic traumatic brain injury: a diffusion tensor imaging study. Brain 2007;130:2508-2519.

25. Henry LC, Tremblay J, Tremblay S, et al. Acute and chronic changes in diffusivity measures after sports concussion. J Neurotrauma 2011;28:2049-2059.

26. Mayer AR, Ling JM, Yang Z, Pena A, Yeo RA, Klimaj S. Diffusion abnormalities in pediatric mild traumatic brain injury. J Neurosci 2012;32:17961-17969.

27. Wilde EA, McCauley SR, Hunter JV, et al. Diffusion tensor imaging of acute mild traumatic brain injury in adolescents. Neurology 2008;70:948-955.

28. Barr WB, Prichep LS, Chabot R, Powell MR, McCrea M. Measuring brain electrical activity to track recovery from sport-related concussion. Brain Inj 2012;26:58-66.

29. Czerniak SM, Sikoglu EM, Liso Navarro AA, et al. A resting state functional magnetic resonance imaging study of concussion in collegiate athletes. Brain Imaging Behav 2014;9:323-332.

30. Cubon VA, Putukian M, Boyer C, Dettwiler A. A diffusion tensor imaging study on the white matter skeleton in individuals with sports-related concussion. J Neurotrauma 2011;28:189-201.

31. Koerte IK, Ertl-Wagner B, Reiser M, Zafonte R, Shenton ME. White matter integrity in the brains of professional soccer players without a symptomatic concussion. JAMA 2012;308:1859-1861.

32. Sollmann N, Echlin PS, Schultz V, et al. Sex differences in white matter alterations following repetitive subconcussive head impacts in collegiate ice hockey players. Neuroimage Clin 2018;17:642-649.

33. Manning KY, Schranz A, Bartha R, et al. Multiparametric MRI changes persist beyond recovery in concussed adolescent hockey players. Neurology 2017;89:2157-2166.

34. Slobounov SM, Walter A, Breiter HC, et al. The effect of repetitive subconcussive collisions on brain integrity in collegiate football players over a single football season: a multi-modal neuroimaging study. Neuroimage Clin 2017;14:708-718.

35. Guskiewicz KM, McCrea M, Marshall SW, et al. Cumulative effects associated with recurrent concussion in collegiate football players. JAMA 2003;290:2549.

36. Slobounov S, Slobounov E, Sebastianelli W, Cao C, Newell K. Differential rate of recovery in athletes after first and second concussion episodes. Neurosurgery 2007; $61: 338-344$. 


\section{Neurology}

\section{Longitudinal changes of brain microstructure and function in nonconcussed female rugby players}

Kathryn Y. Manning, Jeffrey S. Brooks, James P. Dickey, et al.

Neurology 2020;95;e402-e412 Published Online before print June 17, 2020

DOI 10.1212/WNL.0000000000009821

This information is current as of June 17, 2020

\section{Updated Information \&} Services

References

Citations

Subspecialty Collections

Permissions \& Licensing

Reprints including high resolution figures, can be found at: http://n.neurology.org/content/95/4/e402.full

This article cites 36 articles, 8 of which you can access for free at: http://n.neurology.org/content/95/4/e402.full\#ref-list-1

This article has been cited by 3 HighWire-hosted articles: http://n.neurology.org/content/95/4/e402.full\#\#otherarticles

This article, along with others on similar topics, appears in the following collection(s):

\section{Brain trauma}

http://n.neurology.org/cgi/collection/brain_trauma

\section{DWI}

http://n.neurology.org/cgi/collection/dwi

fMRI

http://n.neurology.org/cgi/collection/fmri

MRI

http://n.neurology.org/cgi/collection/mri

Information about reproducing this article in parts (figures,tables) or in its entirety can be found online at:

http://www.neurology.org/about/about_the_journal\#permissions

Information about ordering reprints can be found online:

http://n.neurology.org/subscribers/advertise

Neurology ${ }^{\circledR}$ is the official journal of the American Academy of Neurology. Published continuously since 1951, it is now a weekly with 48 issues per year. Copyright Copyright ( 2020 The Author(s). Published by Wolters Kluwer Health, Inc. on behalf of the American Academy of Neurology.. All rights reserved. Print ISSN: 0028-3878. Online ISSN: 1526-632X.

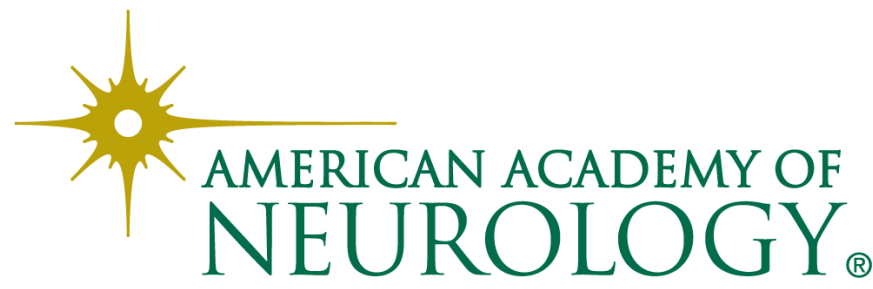

